\title{
IMPLEMENTASI PENERAPAN SASARAN KESELAMATAN PASIEN \\ DI RUMAH SAKIT
}

\author{
Nuraini Sihite \\ Email: nurainisihite4@gmail.com
}

\section{Latar belakang}

Keselamatan pasien menjadi isu global dan terangkum dalam lima isu penting yang terkait di rumah sakit yaitu keselamatan pasien, keselamatan pekerja atau petugas kesehatan, keselamatan bangunan dan peralatan di rumah sakit yang bisa berdampak terhadap keselamatan pasien dan petugas. Keselamatan lingkungan yang berdampak terhadap pencemaran lingkungan dan keselamatan bisnis rumah sakit yang terkait dengan kelangsungan hidup rumah sakit. Keselamatan pasien merupakan prioritas utama untuk dilaksanakan terkait dengan isu mutu dan citra perumahsakitan. Gerakan (Patient Safety) keselamatan pasien telah menjadi spirit dalam pelayanan rumah sakit seluruh dunia tidak hanya rumah sakit di negara maju yang menerapkan keselamatan pasien untuk menjamin mutu pelayanan, tetapi juga rumah sakit di negara berkembang seperti di Indonesia (Depkes, 2006).

Kementerian Kesehatan Republik Indonesia telah mengeluarkan Peraturan Menteri Kesehatan No. 11 Tahun 2017 tentang Keselamatan Pasien di Rumah Sakit. Peraturan ini menjadi tonggak utama operasionalisasi keselamatan pasien di rumah sakit seluruh Indonesia. Banyak rumah sakit di Indonesia yang telah berupaya membangun dan mengembangkan keselamatan pasien, namun upaya tersebut dilaksanakan berdasarkan pemahaman manajemen terhadap keselamatan pasien. Peraturan menteri ini memberikan panduan bagi manajemen rumah sakit agar dapat menjalankan spirit keselamatan pasien secara utuh.

Keselamatan Pasien adalah suatu sistem yang membuat asuhan pasien lebih aman, meliputi assesment risiko, identifikasi dan pengelolaan risiko pasien, pelaporan dan analisis insiden, kemampuan belajar dari insiden dan tindak lanjutnya, serta implementasi solusi untuk meminimalkan timbulnya risiko dan mencegah terjadinya cedera yang disebabkan oleh kesalahan akibat melaksanakan suatu tindakan atau tidak mengambil tindakan yang seharusnya diambil (Permenkes, 2011 dalam Nanda 2018). 


\section{Metode}

Metode yang digunakan pada kajian ini adalah metode kualitatif yang memberikan penjelasan dengan menggunakan analisis pada referensi yang digunakan. Untuk mengumpulkan data-data dari beberapa jurnal dan e-book dari situs internet yang berhubungan dengan topik pembahasan. Karena keterbatasan waktu, cakupan luas dari topik, dan untuk lebih spesifik, maka dilakukan batasan waktu pada tahun publikasinya dengan waktu minimalnya delapan tahun terakhir yaitu dari tahun 2012 dengan mengambil referensi yang terkait dengan topik yang digunakan.

\section{Hasil}

Hasil dari literatur review didapatkan bahwa pengetahuan implementasi sasaran keselamatan pasien di rumah sakit khususnya identifikasi pasien sangatlah penting bagi calon perawat karena dengan mengetahui permentasi sasaran keselamatan pasien dapat mencegah terjadinya insiden keselamatan pasien.

Jurnal analisis pelaksanaan sasaran keselamatan pasien di rawat inap rumah sakit umum daerah Padang Pariaman. Peneliti Reno Afriza Neri, Yuniar Lestari, dan Husna Yetti. Hasil penelitian menunjukkan bahwa kebijakan dan SPO sudah lengkap. Tenaga penanggung jawab keselamatan pasien dalam hal ini tim keselamatan pasien belum bekerja optimal. Metode sudah sesuai dengan pedoman yang ada dan dana sudah mencukupi namun pengadaan sarana belum lengkap. Kepatuhan petugas dalam pelaksanaan sasaran keselamatan pasien belum optimal, nilai rata-rata capaian 73,4\% (standar 100\%).

Pada jurnal Implementasi Sasaran Keselamatan Pasien di Ruang Raat Inap RSU Kabupaten Tanggerang. Peneliti Mardika Dwi Setiyani Zuhrotunida , Syahridal. Metode Penelitian dalah penelitian deskriptif analitik. Pengambilan sampel menggunakan metode total sampling, dengan total 31 perawat dan 33 pasien. Instrumen pada penelitian ini menggunakan kuesioner dan lembar observasi.

Hasil Penelitian yaitu menunjukkan dari 31 perawat, $77.4 \%$ (24perawat) mengimplementasikan ketepatan identifikasi pasien dengan baik, sedangkan hasil observasi dari 33 pasien sebesar $75.8 \%$ (25 pasien) menggunakan gelang identitas dengan minimal dua identitas dan 33 rekam medik (100\%) teridentifikasi dengan minimal dua identitas. $71 \%$ (22 perawat) mengimplementasikan komunikasi efektif dengan baik dan 90.3\% (28 perawat) 
patuh mengimplementasikan hand hygiene sedangkan hasil observasi $87.1 \%$ (27 perawat) patuh.

Secara keseluruhan capaian implementasikan sasaran keselamatan pasien sebesar $74.2 \%$ (23 perawat) sudah baik, namun belum optimal dan konsisten karena belum mencapai 100\%. Dari hasil uji Chi Square terdapat hubungan antara Pendidikan Terakhir (p-value 0.043), Lama Bekerja (p-value 0.008) dan Pelatihan Patient Safety (p-value 0.043) dengan Implementasi Sasaran Keselamatan Pasien. Peluang terbesar terdapat pada hubungan Pelatihan Patient Safety dengan Implementasi Sasaran Keselamatan Pasien didapatkan nilai Odds Ratio $=13.200$. Rekomendasi yang perlu dilakukan pimpinan keperawatan RSU Kabupaten Tangerang yaitu melakukan monitoring dan mengevaluasi pelaksanaan sasaran keselamatan pasien secara rutin dan memberikan pelatihan secara berkala.

\section{Pembahasan}

Rumah sakit merupakan layanan jasa yang memiliki peran penting bagi kehidupan masyarakat. Rumah sakit merupakan tempat yang sangat kompleks yang terdapat berbagai macam obat, tes dan prosedur, banyak alat dengan teknologinya, berbagai jenis tenaga profesi dan non profesi yang siap memberikan pelayanan pasien 24 jam terus menerus. Keberagaman dan kerutinan pelayanan tersebut apabila tidak dikelola dengan baik dapat menimbulkan peluang untuk terjadinya kesalahan pelayanan yang dapat berakibat terhadap keselamatan pasien.

Tidak lepas dari pengaruh meningkatnya perkembangan teknologi informatika yangsaat ini memberikan kemudahan bagi masyarakat untuk mendapatkan berbagai informasi, termasuk juga informasi tentang hal kesehatan, sehingga pengetahuan masyarakat tentang kesehatan semakin bertambah. Bertambahnya pengetahuan masyarakat tentang kesehatan menuntut pemberi pelayanan kesehatan untuk memberikan pelayanan kesehatan yang lebih baik dan memuaskan. Sehingga banyak rumah sakit berlomba-lomba bagaimana memenangkan persaingan dengan cara memberikan rasa kepuasan pada pelanggan atau pasien.

Keselamatan pasien (patient safety) merupakan suatu variabel untukmengukur dan mengevaluasi kualitas pelayanan keperawatan yang berdampakterhadap pelayanan kesehatan. Program keselamatan pasien bertujuan menurunkan angka Kejadian Tidak Diharapkan 
(KTD) yang sering terjadi pada pasien selama dirawat di rumah sakit sehingga sangat merugikan baik pasien sendiri dan pihak rumah sakit.

Di Indonesia, isu KP mendapat perhatian melalui kehadiran Komite Keselamatan Pasien RS (KKP-RS) tahun 2005, diikuti pencanangan Gerakan Keselamatan Pasien dan diterbitkannya Panduan Nasional Keselamatan Pasien RS (Depkes, 2006, 2008). Pentingnya KP juga termuat dalam Undang Undang Rumah Sakit No. 40 tahun 2009 (UURS 2009), disertai adanya Sistem Pelaporan Sukarela Insiden KTD di RS melalui Peraturan Menteri Kesehatan No. 1691 Tahun 2011 tentang Keselamatan Pasien Rumah Sakit (PMK 1691/2011). Namun,praktek KP masih berlangsung sporadis,dengan protokol bervariasi.

Sasaran Keselamatan Pasien (SKP) menjadi indikator standar dasar yang utama dalam penilaian Akreditasi Rumah Sakit versi 2012 (KARS,2013). Ada 6 (enam) sasaran keselamatan pasien yaitu Ketepatan identifikasi pasien; Peningkatan komunikasi yang efektif; Peningkatan keamanan obat yang perlu diwaspadai; Kepastian tepat-lokasi, tepat-prosedur, tepat-pasien operasi; Pengurangan risiko infeksi terkait pelayanan kesehatan; dan Pengurangan risiko pasien jatuh.

\section{a. Ketepatan Identifikasi Pasien}

Elemen ketepatan identifikasi pasien menurut Permenkes (2011) sebagai berikut: (a)Pasien diidentifikasi menggunakan dua identitas pasien (nama pasien, nomor rekam medis, tanggal lahir, gelang identitas pasien dengan bar-code), tidak boleh menggunakan nomor kamar atau lokasi pasien. (b) Pasien diidentifikasi sebelum pemberian obat, darah, atau produk darah. (c) Pasien diidentifikasi sebelum mengambil darah dan spesimen lain untuk pemeriksaan klinis (d) Pasien diidentifikasi sebelum pemberian pengobatan dan tindakan prosedur.(e) Kebijakan dan prosedur mengarahkan pelaksanaan identifikasi yang konsisten pada semua situasi dan kondisi.

\section{b. Peningkatan Komunikasi yang Efektif}

Elemen peningkatan komunikasi yang efektif menurut Permenkes (2011) sebagai berikut: a. Perintah lengkap secara lisan dan melalui telepon atau hasil pemeriksaan dituliskan secara lengkap oleh penerima perintah. b. Perintah lengkap lisan dan telpon atau hasil pemeriksaan dibacakan kembali secara lengkap oleh penerima perintah. c. Perintah atau hasil pemeriksaan dikonfirmasi oleh pemberi perintah atau yang menyampaikan hasil pemeriksaan.d. Kebijakan 
dan prosedur mengarahkan pelaksanaan verifikasi keakuratan komunikasi lisan atau melalui telepon secara konsisten.

\section{c. Peningkatan Keamanan Obat yang Perlu Diwaspadai (High-Alert)}

Elemen peningkatan keamanan obat yang perlu diwaspadai menurut Permenkes (2011) a. Kebijakan dan/atau prosedur dikembangkan agar memuat proses identifikasi,sebagai berikut:menetapkan lokasi, pemberian label, dan penyimpanan elektrolit konsentrat. b. Implementasi kebijakan dan prosedur. c. Elektrolit konsentrat tidak berada di unit pelayanan pasien kecuali jika dibutuhkan secara klinis dan tindakan diambil untuk mencegah pemberian yang kurang hati hati di area tersebut sesuai kebijakan. d. Elektrolit konsentrat yang disimpan pada unit pelayanan pasien harus diberi label yang jelas, dan disimpan pada area yang dibatasi ketat (restricted)

\section{d. Kepastian Tepat-Lokasi, Tepat-Prosedue, Dan Tepat-Pasien Operasi}

Elemen kepastian. tepat-lokasi, tepat-prosedue, dan tepat-pasien operasi menurut Permenkes (2011) sebagai berikut: Rumah sakit menggunakan suatu tanda yang jelas dan dimengerti untuk identifikasi lokasi operasi dan melibatkan pasien di dalam proses penandaan. b. Rumah sakit menggunakan suatu checklist atau proses lain untuk memverifikasi saat preoperasi tepat lokasi, tepat prosedur, dan tepat pasien dan semua dokumen serta peralatan yang diperlukan tersedia, tepat, dan fungsional. c. Tim operasi yang lengkap menerapkan dan mencatat prosedur "sebelum insisi/time-out" tepat sebelum dimulainya suatu prosedur/ tindakan pembedahan. d. Kebijakan dan prosedur dikembangkan untuk mendukung proses yang seragam untuk memastikan tepat lokasi, tepat prosedur, dan tepat pasien, termasuk prosedur medis dan dental yang dilaksanakan di luar kamar operasi.

\section{e. Pengurangan Risiko Infeksil Terkait Pelayanan Kesehatan}

Elemen pengurangan risiko infeksi terkait pelayanan kesehatan menurut Permenkes (2011) sebagai berikut: a. Rumah sakit mengadopsi atau mengadaptasi pedoman hand hygiene terbaru yang diterbitkan dan sudah diterima secara umum (al.dari WHO Patient Safety). b. Rumah sakit menerapkan program hand hygiene yang efektif. c. Kebijakan dan/atau prosedur dikembangkan untuk mengarahkan pengurangan secara berkelanjutan risiko dari infeksi yang terkait pelayanan kesehatan. 


\section{f. Pengurangan Risiko Pasien Jatuh}

Elemen pengurangan risiko pasien jatuh menurut Permenkes (2011) menurut Permenkes (2011) sebagai berikut; a. Rumah sakit menerapkan proses asesmen awal atas pasien terhadap risiko jatuh dan melakukan asesmen ulang pasien bila diindikasikan terjadi perubahan kondisi atau pengobatan, dan lain-lain. b. Langkah-langkah diterapkan untuk mengurangi risiko jatuh bagi mereka yang pada hasil asesmen dianggap berisiko jatuh. c. Langkah-langkah dimonitor hasilnya, baik keberhasilan pengurangan cedera akibat jatuh dan dampak dari kejadian tidak diharapkan.

Penerapan keselamatan pasien di rumah sakit dapat dilakukan dengan berbagai cara,mulai dari cara program sederhana sampai dengan program yang kompleks dan terintegrasi. Agar penerapan programtersebut dapat secara sistematis dan terarah maka dalam melaksanakan program diperlukan beberapa tahapan yaitu:

1. Fase persiapan, yaitu: (1) tetapkan kebijakan dan rencana jangka pendek dan program tahunan KP-RS, (2) tetapkan unit kerja yang bertanggung jawab mengelola program KP-RS, (3) pilih penggerak (champion) yang akan jadi motor penggerak KP-RS dan pelatihannya dan (4) buku saku KP-RS

2. Fase pelaksanaan, yaitu: (1) deklarasi gerakan moral keselamatan pasien, (2) program 7 langkah keselamatan pasien, (3) program penerapan standar akreditasi keselamatan pasien, (4) program keselamatan pasien pada unit pelayanan tertentu sebagai model, (5) program khusus, contoh: hand hygiene, ronde keselamatan pasien (RKP),program pelaporan insiden, program bidang farmasi, program pelatihan KP-RS, (6)forum diskusi yang dilakukan secara periodik 1-2 bulan sekali dengan tujuan membahas perkembangan program.

3. Fase evaluasi, yaitu. 2 monitoring dan evaluasi dilakukan secara periodik sesuai dengan kebutuhan untuk perbaikan dan rancangan serta sasaran program selanjutnya

Kemudian Pedoman dan Standar Prosedur Operasiol (SPO) juga merupakan unsur terpenting dalam pelaksanaan suatu kegiatan. SPO berguna untuk menghemat usaha manajerial, memudahkan pendelegasian wewenang dan menempatkan tanggung jawab, menimbulkan pengembangan metode-metode operasional yang lebih efisien, memudahkan pengawasan, memungkinkan penghematan personalia dan membantu kegiatan koordinasi. 


\section{Penutup}

Keselamatan pasien (patient safety) merupakan suatu variabel untukmengukur dan mengevaluasi kualitas pelayanan keperawatan yang berdampakterhadap pelayanan kesehatan. Sasaran Keselamatan Pasien (SKP) menjadi indikator standar dasar yang utama. Ada 6 (enam) sasaran keselamatan pasien yaitu Ketepatan identifikasi pasien; Peningkatan komunikasi yang efektif; Peningkatan keamanan obat yang perlu diwaspadai; Kepastian tepat-lokasi, tepat-prosedur, tepat-pasien operasi; Pengurangan risiko infeksi terkait pelayanan kesehatan; dan Pengurangan risiko pasien jatuh.

\section{Daftar pustaka}

1. Hadi, Irwan. 2017. Manajemen keselamatan pasien. Yogyakarta: Deepublish.

2. Ismainar, Hetty. 2015. Keselamatan pasien di rumah sakit. Yogyakarta: Deepublish.

3. Keles, W, Angelia., dkk. 2015. Analisis Pelaksanaan Standar Sasaran Keselamatan Pasien di Unit Gawat Darurat RSUD Dr. Sam Ratulangi Tondano Sesuai dengan Akreditasi Rumah Sakit Versi 2012. JIKMU, Vol. 5, No. 2.

4. Simamora, R. H. (2018). Buku ajar keselamatanpasienmelaluitimbangterimapasienberbasiskomunikasiefektif: SBAR. Medan: USUpress.

5. Simamora, R. H. (2020). Learning of Patient Identification in Patient Safety Programs Through Clinical Preceptor Models. Medico Legal Update, 20(3), 553-556.

6. Neri, A. R., dkk. 2018. Analisis pelaksanaan sasaran keselamatan pasien dirawat inap rumah sakit umum Padang Pariaman. Jurnal Kesehatan Andalas. 7(Supplement 4)

7. Azizah, N. A., Andayanie Ella. 2020. Faktor yang berhubungan dengan sasaran penerapan patient safety perawat ruang inap RSUD lamadukelleng 2020. Window of Public Health Journal, Vol. 1 No. 2.

8. Setiyani, D. M., Zuhrotunida, Syahridal. 2016. Implementasi sasaran keselamatan pasien di ruang rawat inap RSU kabupaten Tangerang. JKFT, Edisi Nomor 2.

9. Sakinah, S., dkk. 2017. Analisis Sasaran keselamatan pasien dilihat dari aspek pelaksanaan identifikasi pasien dan keamanan obat di RS presiden RSPAD Gatot Soebroto Jakarta. Jurnal kesehatan masyarakat (e-Journal) Volume 5, Nomor 4.

10. Surahmat, R., Meri Neherta, Nurariati. 2019. Hubungan Karakteristik Perawat terhadap Pelaksanaan Sasaran Keselamatan Pasien Pasca Akreditasi Rumah Sakit "X" di Kota Palembang Tahun 2018. Jurnal Ilmiah Universitas Batanghari Jambi Volume 19, Nomor 1. 
11. Juniarti, H. N., Ahmad, A. M. 2018. Penerapan standar keselamatan pasien di rumah sakit umum daerah provinsi Nusa Tenggara Barat. Jurnal Kesehatan Poltekkes Ternate, 11(2).

12. Rasam, A. R. 2017. Analisis Tatakelola Sasaran Keselamatan Pasien Pada Alur Pelayanan Penyakit Sepsis Di Rumah Sakit Tebet 2015. Jurnal Administrasi Rumah Sakit Volume 3, Nomor 2. 